\title{
Optimal design parameters of air suspension systems for semi-trailer truck. Part 2: results and discussion
}

\author{
Nguyen Van Tuan', Le Van Quynh ${ }^{2}$, Vi Thi Phuong Thao ${ }^{3}$, Le Quang Duy ${ }^{4}$ \\ 1,2,4Faculty of Automotive and Power Machinery Engineering, Thai Nguyen University of Technology, \\ Thai Nguyen, Vietnam \\ ${ }^{3}$ Faculty of International Training, Thai Nguyen University of Technology, Thai Nguyen, Vietnam \\ ${ }^{2}$ Corresponding author \\ E-mail: ${ }^{1} n l t u a n @ t n u t . e d u . v n,{ }^{2} l e q u y n h @ t n u t . e d u . v n,{ }^{3} v i p h u o n g t h a o @ t n u t . e d u . v n$, \\ ${ }^{4}$ duylequang.ch@gmail.com
}

Received 25 June 2020; accepted 9 August 2020

DOI https://doi.org/10.21595/vp.2020.21563

Check for updates

Copyright $(\mathrm{C} 2020$ Nguyen Van Tuan, et al. This is an open access article distributed under the Creative Commons Attribution License, which permits unrestricted use, distribution, and reproduction in any medium, provided the original work is properly cited.

\begin{abstract}
Based on the results of model and algorithm in Part1 for searching the optimal design parameters of vehicle suspensions using genetic algorithm, in Part 2, the simulation results with MATLAB Simulink combined with an optimal program are written to search the optimal design parameters of vehicle air suspension systems in two optimal conditions. The optimal results indicate that the DLC values at all axles of vehicle respectively reduce by $9.09 \%, 10.71 \%$, $11.11 \%, 10.81 \%, 8.82 \%$ (in Case 1) and $14.29 \%, 19.23 \%, 20.00 \%, 17.14 \%, 12.12 \%$ (in Case 2 ) in comparison with the original air suspension systems when vehicle moves on the ISO class $\mathrm{C}$ road surface at $v=20 \mathrm{~m} / \mathrm{s}$ and full load. All these things indicate that using the genetic algorithm optimization method does not only reduce the tire dynamic loads acting on road surface but also improves the ride comfort. Finally, the optimum performance of vehicle suspension systems is considered and reassessed under different operating conditions. The evaluation results indicate that the optimum performance of the air suspension systems has better potential to improve the road friendliness which provides a ride comfort for road surfaces and vehicle.
\end{abstract}

Keywords: semi-trailer truck, air suspension system, dynamic load coefficient, genetic algorithm, optimal parameters, road friendliness.

\section{Introduction}

In order to improve the performance of the air suspension system for reducing the negative impact on the road surface, the control and optimization methods for air suspension systems are discussed in some of the following studies such as the control methods: the genetic LQG and PID control were used to control an air suspension system [1], the performance of the air suspension system of heavy trucks was analyzed with semi-active fuzzy control [2] and the two-bag air suspension system for heavy-duty vehicles was analyzed using the multi-body vehicle model [3], the optimization technique available in OptiY with SIMULINK simulation was used to search the optimal parameters of air spring of suspension system using vehicle dynamic model with 2 d.o.f [4], The air suspension system with independent height and stiffness tuning was analyzed and the geometric parameters of air spring were optimized [5], the glowworm swarm optimization proportional-integral-derivative controlling algorithm was designed to optimize magnetorheological damper for air suspensions [6], the vehicle suspension parameters of non-linear air spring was analyzed and optimized by using the multi-objective optimization method [7], and the optimization of suspension geometric parameters was analyzed and optimized using a double-loop multi-objective particle swarm optimization algorithm (DL-MOPSO) when the vehicle operates under various driving conditions [8]. The optimal parameters of the suspension systems as well as drum's isolation system were found out using genetic algorithm (GA) $[9,10]$. Based on the results of model and algorithm in Part 1, the rest of this paper of Part 2 is organized as follows: Optimization of suspension parameters and discussion are presented in Section 2. Section 3 presents the efficiency of the optimal design parameters compared with the 
original design parameters of air suspension systems under the different vehicle operating conditions and the conclusions are given in Section 4.

\section{Optimization of suspension parameters and discussion}

In order to find the optimal design parameters for the air suspension systems of the articulated truck semi-trailer, Matlab/Simulink software is used to simulate the half-vehicle dynamic model with a set of parameters of the articulated truck semi-trailer in Table 1 when the vehicle moves on the ISO class $C$ road surface at $v=20 \mathrm{~m} / \mathrm{s}$ and full load.

Table 1. Parameters of the 5 -axle semi-trailer truck

\begin{tabular}{|c|c|c|c|c|c|}
\hline Parameters & Values & Parameters & Value & Parameters & Values \\
\hline$k_{t 1} /\left(\mathrm{N} \cdot \mathrm{m}^{-1}\right)$ & 647500 & $k_{k} /\left(\mathrm{N} \cdot \mathrm{m}^{-1}\right)$ & 2000000 & $I_{c} / \mathrm{kg} \cdot \mathrm{m}^{2}$ & 2056 \\
\hline$k_{t 2} /\left(\mathrm{N} \cdot \mathrm{m}^{-1}\right)$ & 1185000 & $k_{s} /\left(\mathrm{N} \cdot \mathrm{m}^{-1}\right)$ & 28500 & $l_{1} / \mathrm{m}$ & 2.741 \\
\hline$k_{t 3} /\left(\mathrm{N} \cdot \mathrm{m}^{-1}\right)$ & 1185000 & $c_{k} /\left(\right.$ N.s.m $\left.^{-1}\right)$ & 200000 & $l_{2} / \mathrm{m}$ & 2.229 \\
\hline$k_{t 4} /\left(\mathrm{N} \cdot \mathrm{m}^{-1}\right)$ & 1185000 & $c_{s} /\left(\right.$ N.s.m $\left.{ }^{-1}\right)$ & 9200 & $l_{3} / \mathrm{m}$ & 3.334 \\
\hline$k_{t 5} /\left(\mathrm{N} \cdot \mathrm{m}^{-1}\right)$ & 1185000 & $m_{a 1} / \mathrm{kg}$ & 584 & $l_{4} / \mathrm{m}$ & 1.330 \\
\hline$c_{t 1} /\left(\right.$ N.s.m $\left.^{-1}\right)$ & 258.50 & $m_{a 2} / \mathrm{kg}$ & 735 & $l_{5} / \mathrm{m}$ & 2.960 \\
\hline$c_{t 2} /\left(\right.$ N.s.m $\left.{ }^{-2}\right)$ & 325.00 & $m_{a 3} / \mathrm{kg}$ & 735 & $l_{6} / \mathrm{m}$ & 5.620 \\
\hline$c_{t 3} /\left(\right.$ N.s.m $\left.^{-1}\right)$ & 325.00 & $m_{a 4} / \mathrm{kg}$ & 735 & $l_{7} / \mathrm{m}$ & 2.685 \\
\hline$c_{t 4} /\left(\right.$ N.s.m $\left.{ }^{-1}\right)$ & 325.00 & $m_{a 5} / \mathrm{kg}$ & 735 & $l_{8} / \mathrm{m}$ & 1.115 \\
\hline$c_{t 5} /\left(\right.$ N.s.m $\left.^{-1}\right)$ & 325.00 & $m_{b 1} / \mathrm{kg}$ & 3783 & $l_{9} / \mathrm{m}$ & 0.235 \\
\hline$c_{1} /\left(\right.$ N.s.m $\left.{ }^{-1}\right)$ & 11270 & $m_{b 2} / \mathrm{kg}$ & 24800 & $l_{10} / \mathrm{m}$ & 1.200 \\
\hline$k_{c 1} /\left(\mathrm{N} \cdot \mathrm{m}^{-1}\right)$ & 33860 & $m_{c} / \mathrm{kg}$ & 1208 & $\alpha_{2,3}$ & 0.0708 \\
\hline$k_{c 2} /\left(\mathrm{N} \cdot \mathrm{m}^{-1}\right)$ & 33860 & $m_{s} / \mathrm{kg}$ & 116 & $\alpha_{4,5}$ & 0.0481 \\
\hline$c_{c 1} /\left(\right.$ N.s.m $\left.^{-1}\right)$ & 3650 & $I_{b 1} / \mathrm{kg} \cdot \mathrm{m}^{2}$ & 45819 & $\beta_{2,3}$ & 0.0223 \\
\hline$c_{c 2} /\left(\right.$ N.s.m $\left.^{-1}\right)$ & 3650 & $I_{b 2} / \mathrm{kg} \cdot \mathrm{m}^{2}$ & 195820 & $\beta_{4,5}$ & 0.0399 \\
\hline
\end{tabular}

Operation parameters of genetic algorithm as follows: The population size is 100; The number of generations is 200; Elitism: best seven individuals from each generation were chosen for creation of next population; Mutation: random and adaptive mutations were used; Crossover: just neighboring individuals were crossed; and selection: random [9]. A genetic algorithm program in Matlab are called by Simulink module function using the sim function, the simulation results are calculated after the calculation of the population of the objective function value. The optimal values of the parameters of air suspension systems are obtained by genetic algorithms method in comparison with the original design parameters of air suspension systems with two cases, as shown in Table 2 and Table 3.

Table 2. GA optimization results in Case 1

\begin{tabular}{|c|c|c|}
\hline Air spring suspension parameters & Initial design parameters & GA optimization \\
\hline \multicolumn{3}{|c|}{ Case 1 Optimal design of geometrical parameters of air spring suspension systems } \\
\hline$A_{02} / \mathrm{m}^{2}$ & 0.085 & 0.010 \\
\hline$A_{03} / \mathrm{m}^{2}$ & 0.085 & 0.016 \\
\hline$V_{02} / \mathrm{m}^{3}$ & 0.028 & 0.003 \\
\hline$V_{03} / \mathrm{m}^{3}$ & 0.028 & 0.005 \\
\hline$p_{02} / \mathrm{MPa}$ & 0.692 & 0.428 \\
\hline$p_{03} / \mathrm{MPa}$ & 0.692 & 0.528 \\
\hline$A_{04} / \mathrm{m}^{2}$ & 0.092 & 0.041 \\
\hline$A_{05} / \mathrm{m}^{2}$ & 0.092 & 0.032 \\
\hline$V_{04} / \mathrm{m}^{3}$ & 0.03 & 0.014 \\
\hline$V_{05} / \mathrm{m}^{3}$ & 0.03 & 0.011 \\
\hline$p_{04} / \mathrm{MPa}$ & 0.492 & 0.254 \\
\hline$p_{05} / \mathrm{MPa}$ & 0.492 & 0.260 \\
\hline
\end{tabular}


Table 3. GA optimization results in Case 2

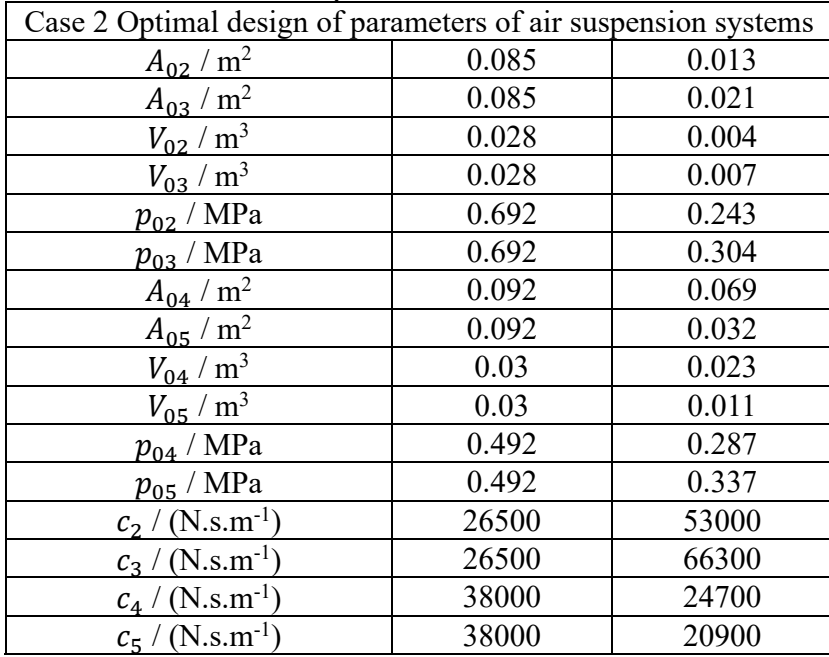

The optimal results of the DLC values at $1 \mathrm{st}, 2 \mathrm{nd}, 3 \mathrm{rd}, 4$ th and 5 th axles of vehicle in comparison with those original results with two cases are shown in Table 4. It is indicated from Table 4 that the DLC values of the optimal design parameters of air suspension systems at all axles of vehicle respectively reduce by $9.09 \%, 10.71 \%, 11.11 \%, 10.81 \%, 8.82 \%$ (in Case 1 ) and $14.29 \%, 19.31 \%, 20.00 \%, 17.14 \%, 12.12 \%$ (in Case 2) in comparison with the original air suspension systems.

All these things indicate that using this genetic algorithm optimization method does not only reduce the tire dynamic loads acting on road surface but also improves the ride comfort.

Table 4. Comparison of optimized results

\begin{tabular}{|c|c|c|c|c|c|}
\hline Parameters and indexes & $\mathrm{DLC}_{\mathrm{t} 1}$ & $\mathrm{DLC}_{\mathrm{t} 2}$ & $\mathrm{DLC}_{\mathrm{t}}$ & $\mathrm{DLC}_{4}$ & $\mathrm{DLC}_{\mathrm{t}}$ \\
\hline Case 1 Optimal design of geometrical parameters of air spring suspension systems \\
\hline Before optimization & 0.024 & 0.031 & 0.030 & 0.041 & 0.037 \\
\hline After optimization & 0.022 & 0.028 & 0.027 & 0.037 & 0.034 \\
\hline Decrease \% & 9.09 & 10.71 & 11.11 & 10.81 & 8.82 \\
\hline Case 2 Optimal design of parameters of air suspension systems \\
\hline Before optimization & 0.024 & 0.031 & 0.030 & 0.041 & 0.037 \\
\hline After optimization & 0.021 & 0.026 & 0.025 & 0.035 & 0.033 \\
\hline Decrease \% & 14.29 & 19.23 & 20.00 & 17.14 & 12.12 \\
\hline
\end{tabular}

The comparison of optimized results of the vertical dynamic tire loads acting on road surface in time domain response at 2nd axle in case 1 and 4th axle in case 2 are show Fig. 1 and Fig. 2. The results from Fig. 1 and Fig. 2 show that the performance optimization of the air suspension systems with two cases is better than the original air suspension systems for reducing the negative impact on road surface, especially when the optimum design parameters of the air suspension systems in case 2 .

\section{Different operating conditions of vehicle}

To evaluate the performance of the optimal design parameters of the air suspension systems on road surface friendliness, the different operating conditions such as road surface roughness, vehicle speed and vehicle load [11-15] are analyzed respectively in this paper. 


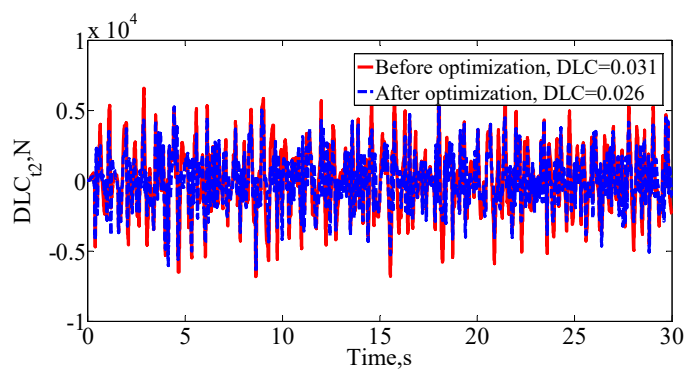

Fig. 1. Comparison of the vertical dynamic tire loads acting on road surface at 2 nd axle in case 1 between before and after optimization

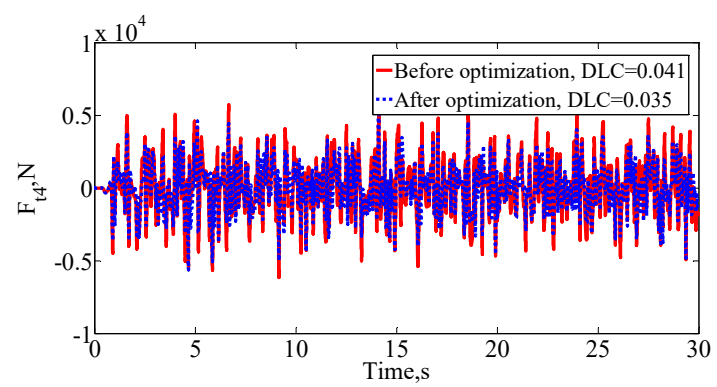

Fig. 2. Comparison of the vertical dynamic tire loads acting on road surface at 4 th axle in case 2 between before and after optimization

\subsection{Effect of road surface roughness}

To evaluate the performance of the optimal design parameters of the air suspension systems in comparing with the original design parameters for reducing the negative impact on road surface with two cases, five road conditions from ISO class A (very good) to ISO class E (very poor) are used when vehicle moves at the vehicle speed of $20 \mathrm{~m} / \mathrm{s}$ and full load. The DLC values at $2 \mathrm{nd}$ and 4th axles of vehicle with three cases are shown in Fig. 3(a). Fig. 3(a) shows that the DLC values at 2 nd and 4th axles of vehicle with the optimal design parameters of air suspension system in case 1 respectively reduce by $10.96 \%, 10.83 \%, 10.71 \%, 9.92 \%, 9.31 \%$ and $10.92 \%, 10.95 \%$, $10.81 \%, 9.35 \%, 9.31 \%$ in comparison with the original air suspension systems of vehicle. Similarly, the DLC values at 2ndand 4th axles of vehicle significantly reduce by $19.19 \%$, $20.00 \%, 19.23 \%, 19.91 \%, 20.38 \%$ and $17.26 \%, 17.34 \%, 17.14 \%, 19.67 \%, 20.00 \%$, respectively in Case 2 .

\subsection{Effect of vehicle speed}

The vehicle speeds of $5 \mathrm{~m} / \mathrm{s}, 10 \mathrm{~m} / \mathrm{s}, 15 \mathrm{~m} / \mathrm{s}, 20 \mathrm{~m} / \mathrm{s}$ and $25 \mathrm{~m} / \mathrm{s}$ are considered to evaluate the performance of the optimal design parameters of the air suspension systems with two cases for a 5- axle semi-trailer truck when vehicle moves on the road surface condition of the ISO class C and full loaded. The DLC values at 2 nd and 4th axles of vehicle with three cases are shown in Fig. 3(b), indicating that the optimal results have a significant improvement in road-friendly level in comparison with the original air suspension systems of vehicle at all vehicle speeds. Moreover, the DLC values at 2ndand 4th axles of vehicle with the optimal design parameters of air suspension system in the optimal results in case 2 are reduced by $6.14 \%, 9.23 \%, 7.95 \%$ and $4.12 \%, 2.31 \%$, $6.33 \%$, respectively in comparison with Case 1 when the vehicle speed increases from 10 to $15 \mathrm{~m} / \mathrm{s}$, and then to $20 \mathrm{~m} / \mathrm{s}$. The DLC values increase or decrease in abnormal manner in each of the vehicle speed because the vehicle speed affects the product of vehicle speed and the cutoff values of the roughness spatial frequency [16]. 

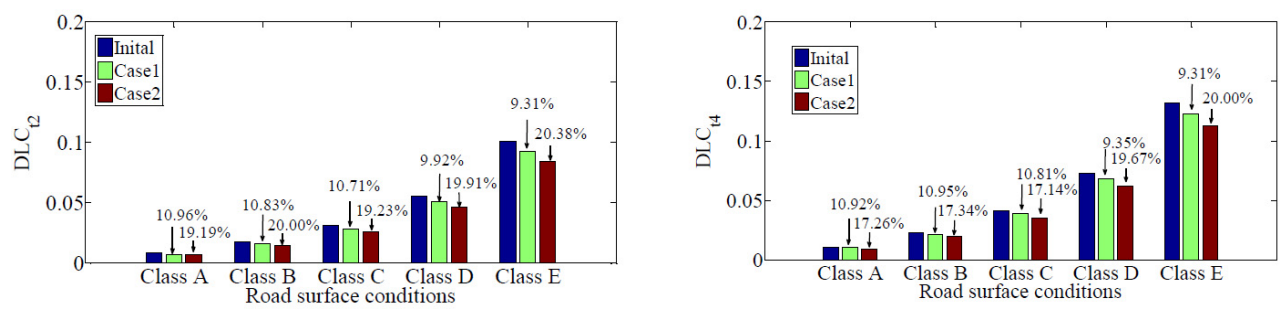

a) Effect of road surface roughness
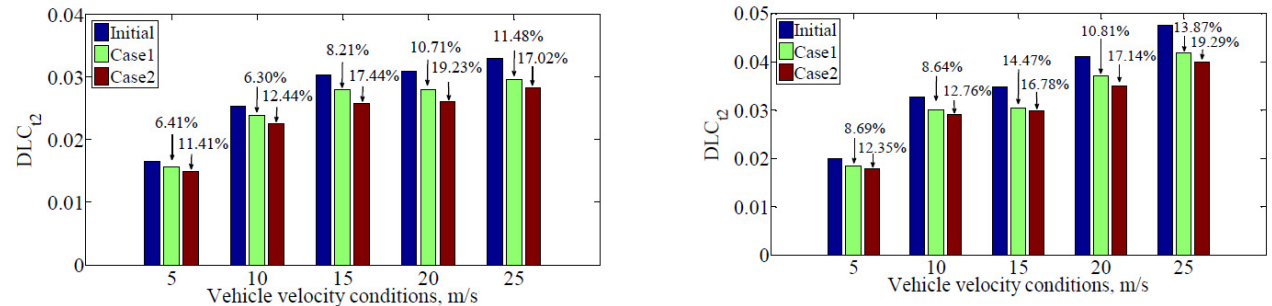

b) Effect of vehicle speed
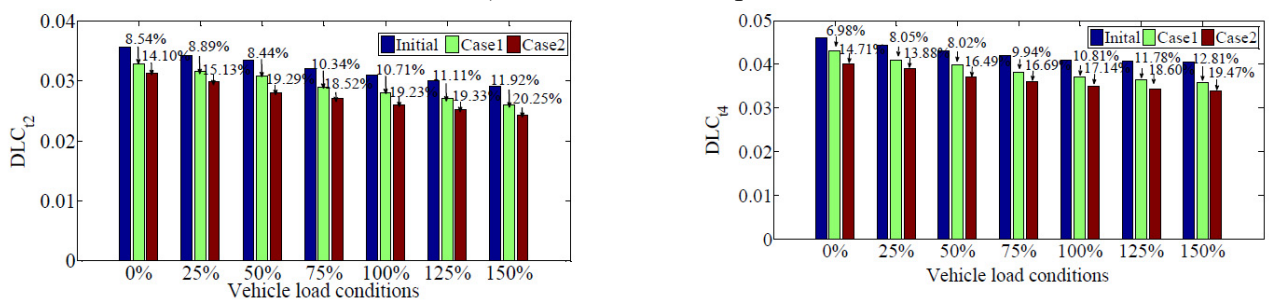

c) Effect of vehicle load

Fig. 3. Comparing of the DLC values at 2 nd and 4th axles of vehicle with three cases

\subsection{Effect of vehicle load}

To continue evaluating the optimal design parameters of the air suspension systems in comparing with the original design parameters for reducing the negative impact on road surface with two cases, seven load conditions of vehicle from $0 \%$ (empty load) to $150 \%$ (over $150 \%$ ) are used when vehicle moves on the road surface condition of the ISO class $\mathrm{C}$ and the vehicle speed of $20 \mathrm{~m} / \mathrm{s}$. The DLC values at $2 \mathrm{nd}$ and 4 th axles of vehicle with three cases are shown in Fig. 3(c). Fig. 3(c) shows that the DLC values at 2nd and 4th axles of vehicle with the optimal design parameters of air suspension system in case 2 significantly reduce by $14.10 \%, 15.13 \%$, $19.29 \%, 18.52 \%, 18.31 \%, 19.33 \%, 20.25 \%$ and $14.71 \%, 13.88 \%, 16.49 \%, 16.69 \%, 17.14 \%$, $18.86 \%, 19.41 \%$, respectively in comparison with the original air suspension systems of vehicle. Moreover, the values of DLC at 2nd and 4th axles of vehicle increase the fastest when vehicle move under $50 \%$ load condition and this problem has a negatively effect on road surface. However, when the vehicle's load increases over $75 \%$ vehicle load, the values of DLC at 2nd and 4 th axles of vehicle reduce gradually, which has a benefit effect on road surface. However, it has no benefit on the durability of the part of vehicle and the safe movement of vehicle [17].

\section{Conclusions}

In part 2 of this study, the simulation results by using MATLAB Simulink combined with an optimal program is written to solve the optimization problem of nonlinear air suspension parameters in two optimal conditions. The obtained the optimization results show that the DLC values of the optimal design parameters of air suspension systems at all axles of vehicle reduce in comparison with the initial air suspension systems of vehicle when vehicle moves on the ISO class 
$\mathrm{C}$ road surface at $v=20 \mathrm{~m} / \mathrm{s}$ and full load. Especially, the DLC values of the optimal design parameters of air suspension systems at $1 \mathrm{st}, 2 \mathrm{nd}$, 3rd 4th and 5th axles of vehicle considering case 2 respectively reduce by $4.76 \%, 7.69 \%, 8.00 \%, 5.71 \%$ and $3.03 \%$ in comparison in Case 1. Finally, the optimum performance of vehicle suspension systems is considered and evaluated again under different operating conditions and the obtained optimization results indicated that the optimum performance is the significant reduction the tire loads and road surface damage. The study results can be used for the searchers, vehicle manufacturers and traffic managers for further considerations during design as well as perfect design in the design of vehicle air suspension systems.

\section{Acknowledgement}

This research was supported financially by Thai Nguyen University of Technology, TNUT, Viet Nam.

\section{References}

[1] Tang Chuan Yin, Li Yun Gong Research on air suspension system based on genetic LQG and PID control. International Conference on Optics, Electronics and Communications Technology, 2017.

[2] Nguyen V., Zhang J., et al. Performance analysis of air suspension of heavy truck with semi-active fuzzy control. Journal of Southeast University (English Edition), Vol. 33, Issue 2, 2017, p. 159-165.

[3] Tajima J., Momiyama F., Yuhara N. A new solution for two-bag air suspension system with leaf spring for heavy-duty vehicle. Vehicle System Dynamics, Vol. 44, Issue 2, 2006, p. 107-138.

[4] Abid H. J., Chen J., Nassar A. A. Equivalent air spring suspension model for quarter-passive model of passenger vehicles. International Scholarly Research Notices, Vol. 2015, 2015, p. 974020.

[5] Karimi Eskandary P., Khajepour A., Wong A., Ansari M. Analysis and optimization of air suspension system with independent height and stiffness tuning. International Journal of Automotive Technology, Vol. 17, Issue 5, 2016, p. 807-816.

[6] Xiao P., Gao H., Shi P., Niu L. Research on air suspension with novel dampers based on glowworm swarm optimization proportional-integral-derivative algorithm. Advances in Mechanical Engineering, Vol. 10, Issue 8, 2018, https://doi.org/10.1177/1687814018791710.

[7] Li J. H., He J., Li X. H. Multi-Objective optimization of vehicle air suspension based on SimulinkMfile mixed programming. Applied Mechanics and Materials, Vol. 509, 2014, p. 63-69.

[8] Yikai Chen, Sen Huang, Lloyd Davis, et al. Optimization of geometric parameters of longitudinalconnected air suspension based on a double-loop multi-objective particle swarm optimization algorithm. Applied Sciences, Vol. 8, Issue 9, 2018, p. 1454.

[9] Goga V., Kl'účik M. Optimization of vehicle suspension parameters with use of evolutionary computation. Procedia Engineering, Vol. 48, 2012, p. 174-179.

[10] Quynh L. V., Thao V. T. P., Phong T. T. Optimal design parameters of drum's isolation system for a double-drum vibratory roller. Vibroengineering Procedia, Vol. 31, 2020, p. 74-79.

[11] Le V. Q. Comparing the performance of suspension system of semi-trailer truck with two air suspension systems. Vibroengineering Procedia, Vol. 14, 2017, p. 220-226.

[12] Long L. X., Hong T. T., et al. Performance analysis of the hydro-pneumatic suspension system of heavy truck. International Journal of Mechanical Engineering and Technology, Vol. 9, Issue 13, 2018 , p. 1128-1139.

[13] Van Cuong B., Van Quynh L., Long L. X. Influence of heavy truck operating condition on dynamic load coefficient. Advances in Engineering Research and Application, 2018, p. 372-379.

[14] Long L. X., Quynh L. V., Cuong B. V. Study on the influence of bus suspension parameters on ride comfort. Vibroengineering Procedia, Vol. 21, 2018, p. 77-82.

[15] Van Quynh L. Influence of semi-trailer truck operating conditions on road surface friendliness. Vibroengineering Procedia, Vol. 16, 2017, p. 67-72.

[16] Shi X. M., Cai C. S. Simulation of dynamic effects of vehicles on pavement using a 3D interaction model. Journal of Transportation Engineering, Vol. 135, Issue 10, 2009, p. 736-744.

[17] Le V. Q., Zhang J., Liu X., Wang Y. Nonlinear dynamic analysis of interaction between vehicle and road surfaces for 5-axle heavy truck. Journal of Southeast University, Vol. 27, Issue 4, 2011, p. 405-409. 